\title{
A soft hood improves maneuverability in narrow spaces during pharyngeal endoscopic submucosal dissection
}

Endoscopic submucosal dissection (ESD) is a minimally invasive treatment for superficial pharyngeal cancer [1]. However, maneuvering the scope is more difficult in working spaces that are narrowed by anatomical features, such as the larynx and thyroid cartilage, or by equipment, such as intubation tubes, laryngoscopes, and grasping forceps. Transparent hoods are widely used for ESD in all gastrointestinal sections to secure the visual field and provide traction, but their long tips and larger outer diameters can obstruct surrounding structures during a pharyngeal ESD. We therefore used a soft, bendable transparent hood (Space adjuster; TOP Corporation, Tokyo, Japan) for pharyngeal ESDs to improve maneuverability in tight working spaces ( $\triangleright$ Video 1 ).

\section{Case 1}

An 18-mm lesion was located at the left pyriform sinus ( Fig.1a). As its oral edge (red arrowhead) was close to an aryepiglottic fold, we were concerned about intrusion by the intubation tube during the incision. We therefore used a soft hood, which bent with its surroundings, thus reducing interference with the intubation tube ( $\mathbf{F i g} \mathbf{1} \mathbf{b}$ ).

\section{Case 2}

Three small lesions (5 to $8 \mathrm{~mm}$ ) that were located at the left pyriform sinus ( Fig.2a) were resected en bloc. We used a soft hood to avoid occluding the larynx and blocking the grasping forceps during ESD ( $>$ Fig. 2 b).

In conclusion, these procedures were stably performed, even in narrow working spaces, using a soft hood during pharyngeal ESD.

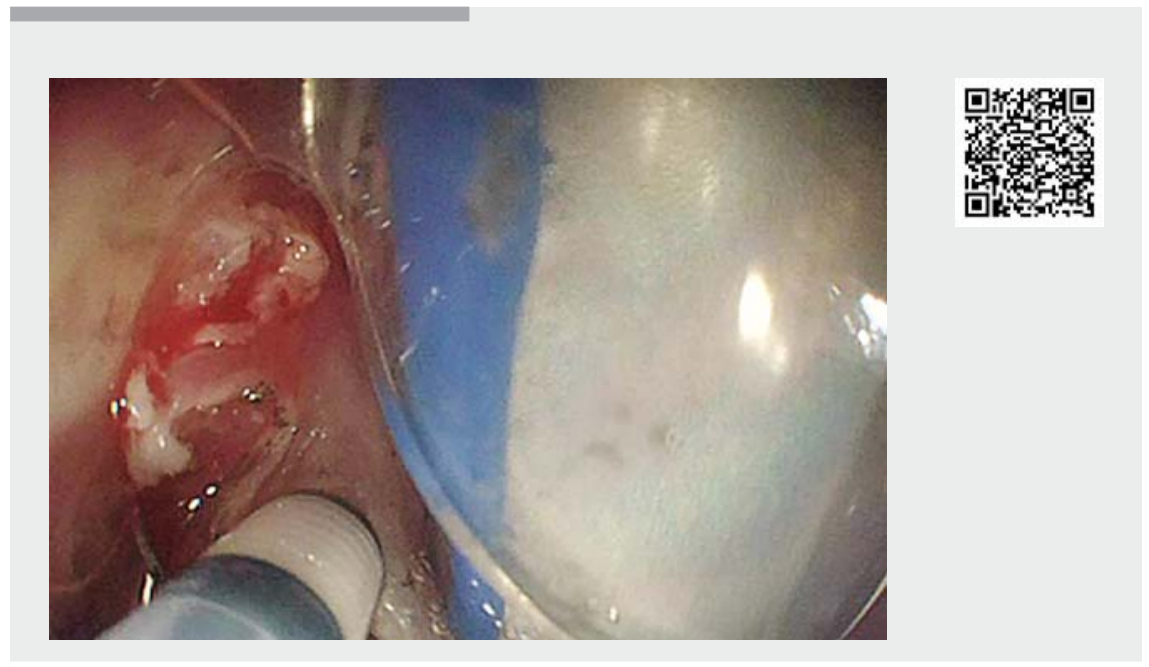

Video 1 A soft hood that bends in narrow working spaces improves endoscope maneuverability.
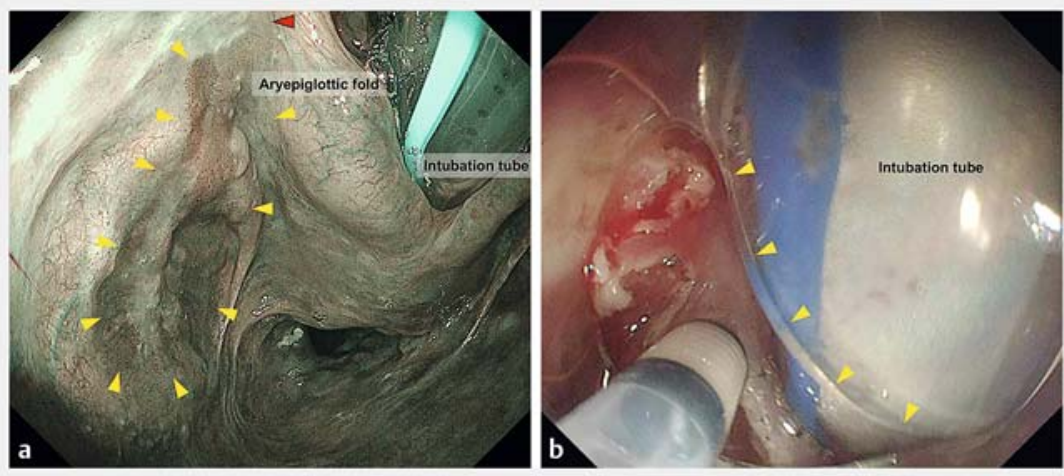

- Fig. 1 Case 1: an 18-mm lesion on the left pyriform sinus. a Endoscopic image of narrowband imaging (arrowheads: lesions). Oral edge of this lesion (red arrowhead) was close to an aryepiglottic fold. b Endoscopic image during endoscopic submucosal dissection. The soft hood bent.

Endoscopy_UCTN_Code_TTT_1AO_2AD, Endoscopy_UCTN_Code_TTT_1AQ_2AJ

\section{Competing interests}

The authors declare that they have no conflict of interest. 

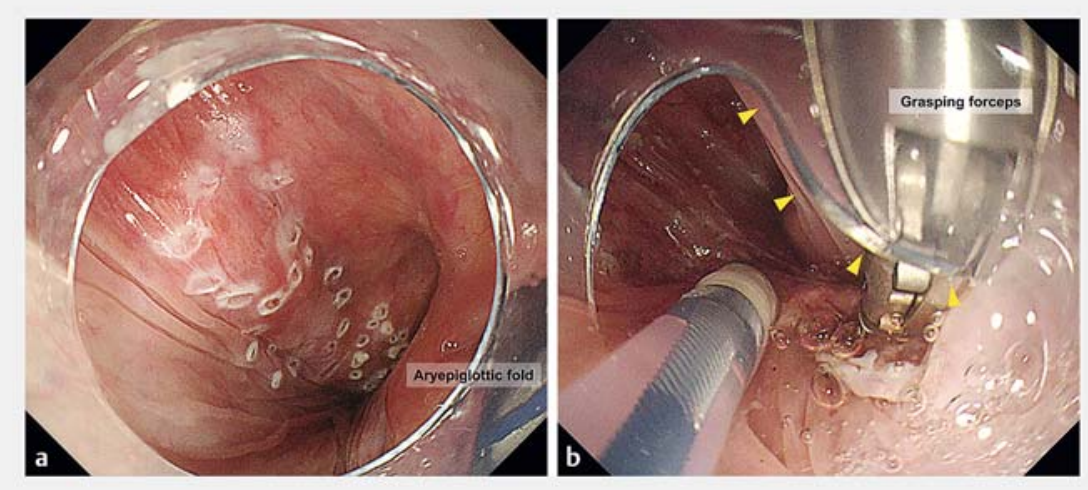

- Fig. 2 Case 2: the lesions on the left pyriform sinus. a Endoscopic image of white-light endoscopy. Three small lesions ( 5 to $8 \mathrm{~mm}$ ) are marked. b Endoscopic image during endoscopic submucosal dissection. A soft hood bent.

The authors

Kotaro Waki ${ }^{1}$, Takashi Kanesaka ${ }^{1}$, Ryu Ishihara', Muneaki Miyake' ${ }^{1}$, Tomoki Michida', Takashi Fujii ${ }^{2}$

1 Department of Gastrointestinal Oncology, Osaka International Cancer Institute, Osaka, Japan

2 Department of Head and Neck Surgery, Osaka International Cancer Institute, Osaka, Japan

\section{Corresponding author}

\section{Takashi Kanesaka, MD}

Department of Gastrointestinal Oncology, Osaka International Cancer Institute, 3-1-69 Otemae, Chuo-ku, Osaka 541-8567, Japan Fax: +81-6-6945-1902

takashikanesaka@gmail.com

\section{Reference}

[1] Hanaoka N, Ishihara R, Takeuchi Y et al. Endoscopic submucosal dissection as minimally invasive treatment for superficial pharyngeal cancer: a phase II study (with video). Gastrointest Endosc 2015; 82: 10021008
Bibliography

Endoscopy 2021; 53: E384-E385

DOI 10.1055/a-1304-3234

ISSN 0013-726X

published online 9.12.2020

(C) 2020. Thieme. All rights reserved.

Georg Thieme Verlag KG, Rüdigerstraße 14 , 70469 Stuttgart, Germany

\section{ENDOSCOPY E-VIDEOS}

https://eref.thieme.de/e-videos

口回 Endoscopy E-Videos is a free 整视 靣舴: on interesting cases and new techniques in gastroenterological endoscopy. All papers include a high quality video and all contributions are freely accessible online.

This section has its own submission website at https://mc.manuscriptcentral.com/e-videos 